\title{
A retrospective cohort study of factors relating to the longitudinal change in birth weight
}

\author{
Kelly S. Gibson ${ }^{1 *}$, Thaddeus P. Waters ${ }^{2}$, Douglas D. Gunzler ${ }^{3}$ and Patrick M. Catalano ${ }^{1}$
}

\begin{abstract}
Background: Recent reports have shown a decrease in birth weight, a change from prior steady increases. Therefore we sought to describe the demographic and anthropometric changes in singleton term fetal growth.

Methods: This was a retrospective cohort analysis of term singleton deliveries (37-42 weeks) from January 1, 1995 to January 1, 2010 at a single tertiary obstetric unit. We included all 43,217 neonates from term, singleton, nonanomalous pregnancies. Data were grouped into five 3-year intervals. Mean and median birth weight (BW), birth length (BL), and Ponderal Index (PI) were estimated by year, race and gestational age. Our primary outcome was change in BW over time. The secondary outcomes were changes in BL and PI over time.

Results: Mean and median BW decreased by 72 and $70 \mathrm{~g}$ respectively $(p<0.0001)$ over the 15 year period while BL also significantly decreased by $1.0 \mathrm{~cm}(P<0.001)$. This contributed to an increase in the neonatal $\mathrm{Pl}$ by $0.11 \mathrm{~kg} / \mathrm{m}^{3}$ $(P<0.001)$. Mean gestational age at delivery decreased while maternal BMl at delivery, hypertension, diabetes, and African American race increased. Adjusting for gestational age, race, infant sex, maternal BMl, smoking, diabetes, hypertension, and parity, year of birth contributed $0.1 \%$ to the variance $(-1.7 \mathrm{~g} / \mathrm{year} ; 26 \mathrm{~g})$ of BW, $1.8 \%(-0.06 \mathrm{~cm} /$ year; $0.9 \mathrm{~cm})$ of $\mathrm{BL}$, and $0.7 \%\left(+0.008 \mathrm{~kg} / \mathrm{m}^{3} /\right.$ year; $\left.0.12 \mathrm{~kg} / \mathrm{m}^{3}\right)$ of PI. These findings were independent of the proportional change in race or gestational age.

Conclusions: We observed a crude decrease in mean BW of $72 \mathrm{~g}$ and BL of $1 \mathrm{~cm}$ over 15 years. Furthermore, once controlling for gestational age, race, infant sex, maternal BMI, smoking, diabetes, hypertension, and parity, we identified that increasing year of birth was associated with a decrease in BW of $1.7 \mathrm{~g} / \mathrm{year}$. The significant increase in PI, despite the decrease in BW emphasizes the limitation of using birth weight alone to define changes in fetal growth.
\end{abstract}

Keywords: Birth weight, Birth length, Ponderal index

\section{Background}

For decades, newborn birth weight has been a focus of clinical investigation as an assessment of fetal growth. During the 1990s several investigators reported a steady increase in newborn birth weight. [1-9] However, more recent investigations have suggested a plateauing [10-12] or a possible reversal in this trend [13-15]. These

\footnotetext{
* Correspondence: kgibson@metrohealth.org

${ }^{1}$ Department of Obstetrics and Gynecology, MetroHealth Medical Center, Case Western Reserve University School of Medicine, 2500 Metrohealth Drive, Cleveland, $\mathrm{OH}$ 44109, USA

Full list of author information is available at the end of the article
}

observations have raised several questions regarding fetal development because of possible long-term sequellae. As fetal growth (both excessive and restricted) is associated with adverse long-term health, further evaluation of these observations is warranted.

The intrauterine environment, genetics, and gestational age all contribute to newborn weight. Maternal factors including hypertensive disorders [16-18], diabetes [19], smoking [20, 21], body mass index (BMI) [22], gestational weight gain [23], and race [24] play key roles in the complex process of fetal growth [25]. The frequency of these variables within the population has not remained constant. Therefore, to more accurately 
evaluate the changes in birth weight over time, one should account for population changes such as the increase in obesity in women of reproductive age [26], comorbid conditions, and changes in obstetric practice $[27,28]$. Additionally, while recent observational studies have noted a decrease in term birth weight, these data are incongruent with the corresponding increase or plateauing in childhood obesity $[29,30]$.

Therefore, the primary aim of this study was to evaluate the change in term singleton newborn birth weight over 15 years at a tertiary inner city hospital, while adjusting for relevant factors that contribute to fetal growth. As a secondary aim, we evaluated the changes in Ponderal Index (an anthropometric estimate of neonatal adiposity analogous to a BMI in adults) during this time period to better estimate the changes in weight for length as a measure of neonatal adiposity.

\section{Methods}

A contemporaneously maintained database was used to examine the impact of maternal demographic characteristics and co-morbid conditions upon fetal growth among term singleton deliveries. In brief, delivery records from the Department of Obstetrics and Gynecology, MetroHealth Medical Center, Cleveland, Ohio, are entered prospectively into a computerized database for research purposes. The data collection began in October 1974, and data such as maternal history, pregnancy complications, and delivery details are ascertained for each patient. Each entry is independently compared with the patient's medical record by an independent reviewer [31]. Only data collected from January 1995 to January 2010 were used as this extended our prior report, which showed an increase in our population's birth weight [31]. This study was reviewed and approved by The MetroHealth System Institutional Review Board. As the study was on de-identified data from a departmental database, it received a waiver of HIPPA and informed consent under an expedited review.

Of the 49,550 singleton non-anomalous live born births recorded between January 1, 1995 and January 1, 2010, 43,217 were included in the analysis. We excluded births with gestational age less than 37 weeks (6287) or greater than 42 completed weeks (38) and records with a birth weight that was inconsistent with gestational age (greater than 2.5 standard deviations) based on the data for United States term birth weight by Alexander et al. [32].

Gestational age was defined by best obstetrical estimate, normally including the patient's last menstrual period with ultrasound confirmation usually less than 20 weeks gestation. In cases where there was a discrepancy, we used the estimated gestational age calculated by ultrasound dating. We queried data on variables relevant to newborn birth weight including maternal age, parity, self-identified race (Caucasian, African-American, Hispanic, Asian, Other, and Declined/no answer), smoking, illicit drug use, prenatal care, weight at delivery, height, complications of pregnancies (hypertensive disorders, diabetes, and bleeding), and mode of delivery. To assess fetal growth, infant birth weight, birth length, weight for length as an estimate of adiposity, and sex were abstracted. Birth weight (BW) was measured at delivery on a scale that is calibrated monthly. Birth length (BL) is measured from the crown of the newborn's head in a neutral position to the heel of the fully extended leg using a disposable tape measure. These methods have been used consistently over the time of our review by our nursing staff. Additionally, we estimated the change in newborn Ponderal Index (PI: calculated as $\mathrm{kg} / \mathrm{m}^{3}$ ) over time as a marker of fetal weight for length an estimate of adiposity [33].

The change in newborn BW, BL and PI in addition to changes in patient demographics and medical comorbidities were analyzed as 3 year intervals to examine trends over time. We used the Cochran-Armitage test for trend for the binary variables, nulliparity, smoking, cesarean delivery, hypertension, diabetes mellitus, and infant sex. We used regression analysis with contrasts for testing a linear trend across the 3 year intervals for the continuous variables (maternal age, BMI, percent African American, mean and median BW, gestational age, BL, and PI). We also described the total change from 1995 to 2010 of each of these variables. Additionally, the changes in mean and median BW were estimated by year, race and gestational age.

We initially evaluated if the changes in BW, BL and PI (dependent variables) over time were correlated with the changes in all available independent variables (maternal age, parity, BMI at delivery, race, smoking, diabetes mellitus, and hypertension and neonatal gestational age) in univariate correlation analyses (Additional file 1: Table S1). We then included all the significant and clinically relevant independent variables into multiple regression models for each outcome (BW, BL and PI). These multivariate models were used to determine the contribution of each independent variable, adjusted for the potential confounding of other included variables, with BW BL and PI, respectively. We tested for multi-colinearity by examining the correlation between predictors (Additional file 1: Table S2). The covariates for race, parity, infant sex, smoking, diabetes, and hypertension were treated as binary variables in our final models. Further, the interaction between race and sex was explored in the analyses. Separate regressions were performed for each race and compared with the Chow test.

A $p$ value $<0.05$ was considered significant. All statistical analysis was done using Statview 5.01 (Cary, NC) and SAS Version 9.2 (Cary, NC SAS Institute Inc). Due 
to the large sample size in our study, we particularly evaluated the effect size as an indicator of magnitude of each relationship.

\section{Results}

A total of 43,217 singleton newborns were included into our final cohort. Between 1995 and January 1, 2010 mean BW for term singleton deliveries decreased by 72 g. Birth length decreased by $1.0 \mathrm{~cm}$. This contributed to a significant increase over time in the neonatal Ponderal Index of $0.10 \mathrm{~kg} / \mathrm{m}^{3}$ (Fig. 1a-c, Table 1).

Table 1 also presents the changes in maternal and neonatal characteristics for the population over 15 years and in 3 year intervals. Maternal age increased over the 15 -year period by 0.5 years. Self-reported race in the population changed from Caucasian to primarily AfricanAmerican (11.47 \% decrease in Caucasians and $8.18 \%$ increase in African-Americans, Additional file 2: Figure $\mathrm{S} 1 \mathrm{~A})$. The rate of hypertension and hypertensive disorders of pregnancy doubled to $4.67 \%$. Similarly, the prevalence of pre-existing diabetes mellitus also doubled to $2.07 \%$
(Additional file 2: Figure S1B). Patients also became heavier over the study period with an increase in weight of 4 $\mathrm{kg}$ in their weight prior to delivery. Corresponding to the increase in maternal weight without significant change in height, the maternal body mass index (BMI) at delivery increased by a mean of $1.76 \mathrm{~kg} / \mathrm{m}^{2}$. Additional file 2: Figure S1C shows this increase was consistent for all races, although African Americans had higher BMI's than other ethnic groups. Parity remained stable with nearly one in three deliveries to a nulliparous woman. The rate of smoking was constant with $20 \%$ of women using cigarettes of any amount throughout their pregnancy. Gestational age at delivery decreased by a mean of 0.4 weeks, a finding consistent amongst all races (Fig. 1d). Infant sex ratio remained constant (51.1-50.3\% male). The mode of delivery changed with an increase in primary cesarean deliveries from 9.99 to $11.92 \%$ and a doubling in the rate of repeat cesareans from 5.25 to $11.05 \%$.

Because many factors that might affect birth weight changed over time within our cohort, we attempted to assess the contribution of the changes in maternal and

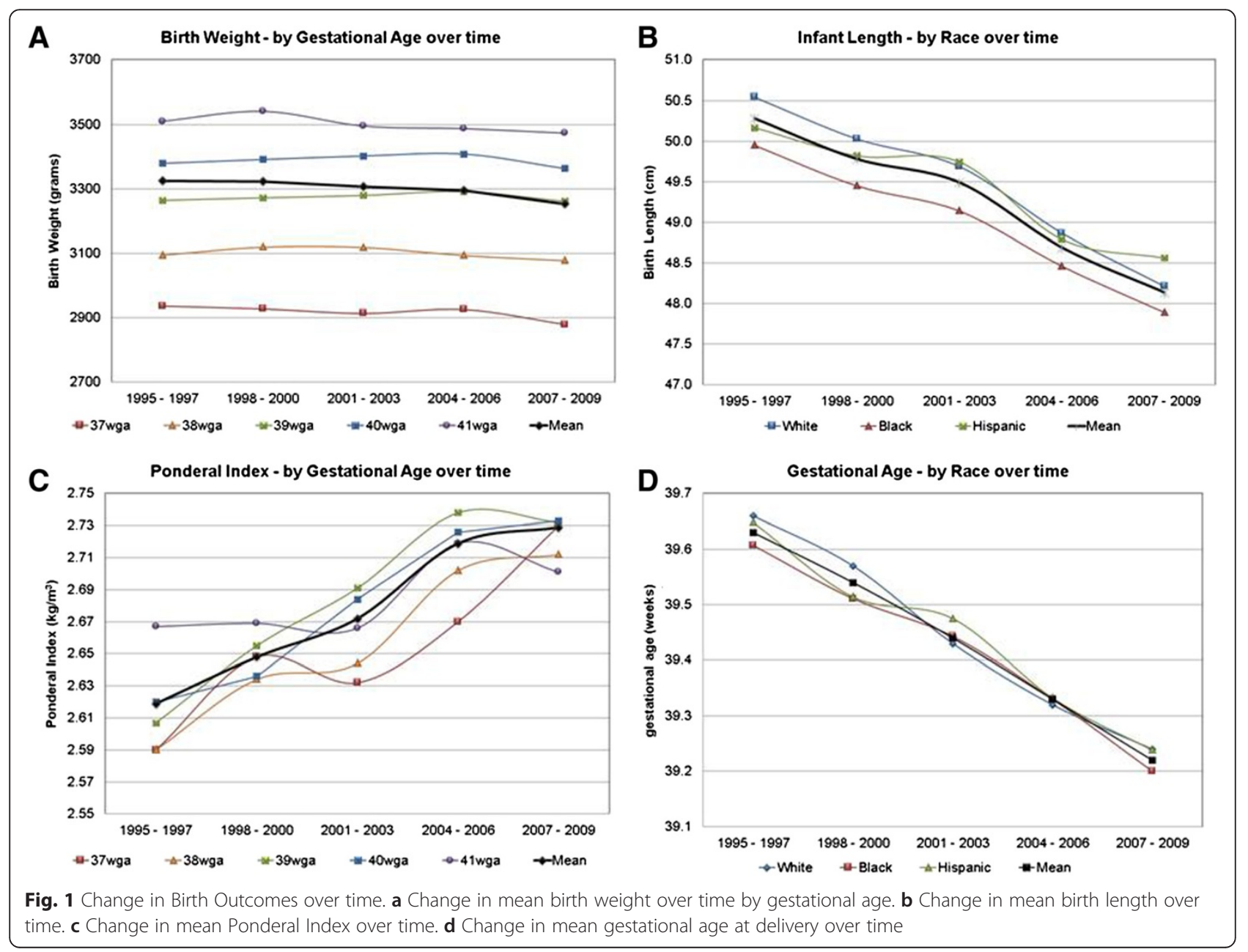


Table 1 Demographic characteristics and outcomes over time

\begin{tabular}{|c|c|c|c|c|c|c|c|}
\hline Variable & $\begin{array}{l}1995-1997 \\
(n=9447)\end{array}$ & $\begin{array}{l}1998-2000 \\
(n=8801)\end{array}$ & $\begin{array}{l}2001-2003 \\
(n=8399)\end{array}$ & $\begin{array}{l}2004-2006 \\
(n=8418)\end{array}$ & $\begin{array}{l}2007-2010 \\
(n=8182)\end{array}$ & $\begin{array}{l}\text { Total Change } \\
\text { Over time }\end{array}$ & $P$ value* \\
\hline $\begin{array}{l}\text { Maternal Age } \\
\text { (years) }\end{array}$ & $25.1(6.2)$ & $25.5(6.2)$ & $25.8(6.3)$ & $25.8(6.2)$ & $25.6(6.2)$ & 0.5 & $<0.001$ \\
\hline Nulliparity (\%) & $39.4 \%$ & $36.5 \%$ & $37.8 \%$ & $38.6 \%$ & $38.8 \%$ & $-0.6 \%$ & 0.684 \\
\hline Smoking (\%) & $20.4 \%$ & $22.2 \%$ & $19.0 \%$ & $21.2 \%$ & $20.2 \%$ & $-0.2 \%$ & 0.383 \\
\hline Cesarean (\%) & $16.1 \%$ & $16.0 \%$ & $20.1 \%$ & $23.0 \%$ & $22.9 \%$ & $6.8 \%$ & $<0.001$ \\
\hline BMI (kg/m2) & $30.9(6.6)$ & $31.6(6.7)$ & $31.9(6.9)$ & $32.4(7.2)$ & $32.7(7.3)$ & 1.8 & $<0.001$ \\
\hline Hypertension (\%) & $2.4 \%$ & $2.9 \%$ & $2.8 \%$ & $4.2 \%$ & $4.7 \%$ & $2.3 \%$ & $<0.001$ \\
\hline Diabetes (\%) & $3.2 \%$ & $4.4 \%$ & $5.2 \%$ & $5.3 \%$ & $4.8 \%$ & $1.6 \%$ & $<0.001$ \\
\hline \%African American & $37.2 \%$ & $38.3 \%$ & $38.1 \%$ & $42.1 \%$ & $45.4 \%$ & $8.2 \%$ & $<0.001$ \\
\hline Mean BW (g) & $3325(483)$ & $3324(481)$ & $3307(475)$ & $3295(467)$ & $3253(457)$ & -72 & $<0.001$ \\
\hline Median BW (g) & 3310 [3010-3635] & 3305 [3005-3630] & 3295 [3995-3605] & 3280 [2995-3590] & 3240 [2955-3545] & -70 & $<0.0001$ \\
\hline Infant Sex (\%Male) & $51.1 \%$ & $50.8 \%$ & $50.0 \%$ & $50.7 \%$ & $50.3 \%$ & $-0.8 \%$ & 0.283 \\
\hline $\begin{array}{l}\text { Gestational Age } \\
\text { (weeks) }\end{array}$ & $39.6(1.3)$ & $39.5(1.3)$ & $39.4(1.3)$ & $39.3(1.2)$ & $39.2(1.2)$ & -0.4 & $<0.001$ \\
\hline Mean BL (cm) & $50.4(2.5)$ & $50.1(2.5)$ & $50.0(2.6)$ & $49.6(2.6)$ & $49.4(2.5)$ & -1.0 & $<0.001$ \\
\hline Mean PI $\left(\mathrm{kg} / \mathrm{m}^{3}\right)$ & $2.61(0.33)$ & $2.64(0.32)$ & $2.66(0.34)$ & $2.71(0.36)$ & $2.71(0.35)$ & 0.10 & $<0.001$ \\
\hline
\end{tabular}

Data presented as mean (standard deviation), median [interquartile range], or percentage; $B M I$ body mass index, $B W$ birth weight, $B L$ birth length, $P I$ ponderal index

${ }^{*} P$ value listed in this table are from the Cochran-Armitage test for trend for binary variables (nulliparity, smoking, cesarean delivery, hypertension, diabetes mellitus, and infant sex) and linear regression analysis using contrasts to test for a linear trend for continuous variables (maternal age, BMI, percent African American, mean and median $\mathrm{BW}$, gestational age, $\mathrm{BL}$, and $\mathrm{PI}$ )

newborn factors to the changes in BW, BL and PI using multiple regression. After assessing the correlation of each independent maternal and neonatal variable with BW, the clinically relevant and significant $(P<0.05)$ factors were included in the multiple regression model (Table 2). Similar regression analyses were performed for BL (Table 3) and PI (Table 4). In the multivariable regression model, after adjusting for potential confounders, we observed that every one unit increase in gestational age maternal BMI at delivery, and parity were associated with increases in birth weight. Male sex and pre-pregnancy diabetes were also associated with increases in birth weight in the regression model. Conversely, African American race, smoking, hypertension, and year of delivery were all associated with decreases in BW. Maternal smoking, African American race, year of delivery, and maternal hypertension were associated with a significant decrease in neonatal length while maternal BMI at delivery, parity, year of delivery, maternal diabetes, and gestational age were all associated with a significant increase in Ponderal Index.

Further, the interaction between race and sex was explored in the analyses. Separate regressions were performed for each race and compared with the Chow test. While the test did find a significant difference between the races $(P<0.001)$, in examining the actual magnitude of

Table 2 Estimated change in newborn birth weight by relevant maternal and newborn factors

\begin{tabular}{|c|c|c|c|c|c|}
\hline- & $r$ & Parameter Estimate & Standard Error & T-statistic & $P$ Value \\
\hline Gestational Age (weeks) & 0.367 & 139.1 & 1.65 & 84.13 & $<0.0001$ \\
\hline $\mathrm{BMI}\left(\mathrm{kg} / \mathrm{m}^{2}\right)$ & 0.198 & 13.5 & 0.3 & 44.86 & $<0.0001$ \\
\hline African American Race & -0.15 & -145.8 & 4.17 & -34.93 & $<0.0001$ \\
\hline Male Sex & 0.13 & 122.9 & 4.03 & 30.44 & $<0.0001$ \\
\hline Smoking & -0.134 & -156.6 & 5.02 & -31.21 & $<0.0001$ \\
\hline Parity & 0.101 & 98.9 & 4.21 & 23.51 & $<0.0001$ \\
\hline Diabetes & 0.074 & 168.9 & 9.95 & 16.97 & $<0.0001$ \\
\hline Hypertension & -0.029 & -75.5 & 11.34 & -6.65 & $<0.0001$ \\
\hline Year (per one year change) & -0.016 & -1.7 & 0.48 & -3.66 & 0.0003 \\
\hline
\end{tabular}

Results from multiple regression model. Multivariate model adjusted $\mathrm{R}^{2}=0.24$ 
Table 3 Estimated change in newborn birth length by relevant maternal and newborn factors

\begin{tabular}{|c|c|c|c|c|c|}
\hline- & $r$ & Parameter Estimate & Standard Error & T-statistic & $P$ Value \\
\hline Gestational Age (weeks) & 0.31 & 0.632 & 0.009 & 67.43 & $<0.0001$ \\
\hline $\mathrm{BMI}\left(\mathrm{kg} / \mathrm{m}^{2}\right)$ & 0.091 & 0.033 & 0.002 & 19.50 & $<0.0001$ \\
\hline African American Race & -0.108 & -0.56 & 0.024 & -23.69 & $<0.0001$ \\
\hline Male Sex & 0.154 & 0.786 & 0.023 & 34.36 & $<0.0001$ \\
\hline Smoking & -0.115 & -0.721 & 0.028 & -25.36 & $<0.0001$ \\
\hline Parity & 0.000 & 0.003 & 0.024 & 0.13 & 0.9004 \\
\hline Diabetes & 0.032 & 0.394 & 0.057 & 6.96 & $<0.0001$ \\
\hline Hypertension & -0.018 & -0.263 & 0.065 & -4.06 & $<0.0001$ \\
\hline Year (per one year change) & -0.103 & -0.061 & 0.003 & -22.72 & $<0.0001$ \\
\hline
\end{tabular}

Results from multiple regression model. Multivariate model adjusted $R^{2}=0.17$

estimates in the models, they are very similar (adjusted $R^{2}$ $=0.24$ for African American, adjusted $R^{2}=0.23$ for all other races; Additional file 1: Table S3A-B).

\section{Discussion}

Our data corroborate previous reports of a decrease in the term newborn birth weight over time. However, we also describe the significant decrease in birth length and resultant increase in Ponderal Index over time. Many of the changes in birth weight over time can be attributed to changes in obstetric practice and population demographics. Within our population a $72 \mathrm{~g}$ decrease in mean term birth weight was noted from 1995 through January 1,2010 . This was related to multiple factors including a decrease in gestational age at delivery, the increased percentage of African American patients, hypertension, and continued tobacco use.

Our study has several strengths. We used a large number of patients from a well-established, prospectively collected database. The patient population is similar to many inner-city hospitals, thus the results could be generalized to similar populations, but may not be applicable to others. This is one of the first studies of an entire population to report on changes in birth length. The multiple regression controlled for common confounding variables. The methods of measuring neonatal weight and length at birth did not change over the study period. To explore the accuracy of the clinical birth lengths, we analyzed the clinical measure of neonatal length in 450 infants who were also subjects in an anthropomorphic study that included length at birth by a trained research nurse using a measuring board. The measurements correlated well with an $\mathrm{r}=$ $0.67(P<0.001$, unpublished $)$ which did not significantly change over time.

This analysis also has limitations. It was retrospective and limited by what data was available and confined to a single site. The patient population is not representative of the overall population in the United States. Some potential confounders, such as maternal pregravid BMI, gestational weight gain, glycemic control, degree of hypertension, gestational age at first ultrasound, socioeconomic status, and paternal height and weight could not be evaluated. As birth weight is dependent on these and other, unaccounted for factors, the $\mathrm{r}^{2}$ values for

Table 4 Estimated change in newborn ponderal index by relevant maternal and newborn factors

\begin{tabular}{|c|c|c|c|c|c|}
\hline- & $r$ & Parameter Estimate & Standard Error & T-Statistic & $P$ Value \\
\hline Gestational Age (weeks) & 0.046 & 0.013 & 0.001 & 9.27 & $<0.0001$ \\
\hline $\mathrm{BMI}\left(\mathrm{kg} / \mathrm{m}^{2}\right)$ & 0.111 & 0.006 & 0 & 22.35 & $<0.0001$ \\
\hline African American Race & -0.039 & -0.028 & 0.003 & -8.06 & $<0.0001$ \\
\hline Male Sex & -0.041 & -0.028 & 0.003 & -8.56 & $<0.0001$ \\
\hline Smoking & -0.013 & -0.011 & 0.004 & -2.73 & 0.006 \\
\hline Parity & 0.109 & 0.077 & 0.003 & 22.43 & $<0.0001$ \\
\hline Diabetes & 0.044 & 0.073 & 0.008 & 8.94 & $<0.0001$ \\
\hline Hypertension & -0.012 & -0.022 & 0.009 & -2.40 & 0.02 \\
\hline Year (per one year change) & 0.114 & 0.009 & 0 & 23.44 & $<0.0001$ \\
\hline
\end{tabular}

Results from multiple regression model. Multivariate model adjusted $\mathrm{R}^{2}=0.05 ; \mathrm{BMI}$ body mass index 
multivariate analyses for BW, BL, and PI were each relatively low $(0.05-0.24)$. Thus, while the variables entered into our model, including year, were significantly correlated, many other factors as described above may also affect the changes seen in BW over time.

Several previous studies have reported the change in BW over time in large populations. In 2010 Donahue et al. reported a $52 \mathrm{~g}$ decrease in mean newborn BW amongst 36,827,828 deliveries over 15 years in a national birth certificate database [13]. Similar to our findings, the decrease remained significant after controlling for gestational age at delivery, maternal age, race, parity, smoking, weight gain, and medical comorbidities. Zhang et al. found a significant association between the increasing use of labor inductions and the decline in gestational age and $\mathrm{BW}$, proposing that the change in BW was due more to decreases in gestational age from alterations in obstetric practice rather than neonatal biometric changes [14]. Schiessel et al. assessed 695,707 mother-infant pairs in Bavaria and found an increase in maternal weight gain yet a decrease in BW of nineteen grams [15]. These results are consistent with our finding of increasing maternal BMI at delivery, but the Schiessel study did not adjust for the decrease in gestational age. As term fetuses gain approximately $10-20 \mathrm{~g} /$ day [32], changes in gestational age may have accounted for the some of the change in mean birth weight. Morisaki et al. reported that in a population where length of gestation at term did not change, birth weight and fetal growth declined. Differences geography, ethnicity of the study population, and the prevalence of overweight and obesity may explain some of these differences in Morisaki's results and our findings [34].

The majority of the decrease in birth weight over time was related to concomitant changes in maternal demographics, especially race and comorbidities, and gestational age. This suggests that the single parameter of birth weight alone may be an insufficient assessment of intrauterine growth. Our study is among the first to consider neonatal length and the Ponderal Index in our evaluating trends in fetal growth. The trend of a decrease in birth weight and length is clinically important insomuch as it represents a change in intrauterine growth which has potential long-term implications for both child and adult health, relative to fetal programming and increasing adiposity.

The concept of decreased neonatal length has also been referred to as stunting or decreased crown-heel length for gestational age [35]. Stunting has primarily been related to inadequate nutrition during pregnancy and the first years of life [36]. However, based on our findings of a $4.2 \%$ decrease in length and increases in maternal metabolic syndrome of pregnancy, i.e., hypertension, diabetes, and BMI at delivery, we may be observing the effects of the broader definition of malnutrition, i.e., a diet poor in healthy nutrients but with a surfeit of poor quality calories. Being born short increases the risk of adult shortness [37] and related problems and may be a surrogate for lean body mass. The ratio of fat to lean body mass may be a better predictor of later metabolic disease than either anthropometric measure alone.

How useful is the concept of Ponderal Index in assessing fetal growth? Rohrer first proposed the term in 1921 as the "corpulence index" used to evaluate growth in neonates and children after World War I in Germany (33The term is useful because mass/volume (length ${ }^{3}$ ) is the definition of density used in many formulations of body composition. In a sample of 215 Caucasian, African American and Hispanic neonates, there was a significant correlation between Ponderal Index and percent body fat using air densitometry or Pea Pod $(\mathrm{R}=0.40, \quad P=<0.001$, see Additional file 3: Figure S2). Hence the concern is that the decrease in birth weight relating to demographic and practice patterns may be more than offset by other factors affecting fetal length and possibly lean body mass relative to long-term health of the neonate. The change in Ponderal Index from 1995 to 1997 to 2007-2009 (2.61 to2.71) represents approximately a $10 \%$ increase in Ponderal Index over time.

\section{Conclusions}

In summary, consistent with recent reports we found a decrease in mean birth weight over time. The majority of this change can be attributed to variations in demographic factors and obstetrical practice affecting fetal growth. We also noted a significant decrease in length at birth and increase in Ponderal Index over time. These data stress the importance of considering factors beyond birth weight alone in the assessment of fetal growth. The increases in maternal BMI coupled with the increased Ponderal Index as an estimate of neonatal adiposity are consistent with the concept of developmental programming relating to the increase in the worldwide obesity epidemic.

\section{Additional files}

Additional file 1: Table S1. Univariate Pearson correlation coefficients between independent variables and birth weight, birth length, and ponderal index. Table S2. Univariate Pearson correlation coefficients between independent variables to assess for multicollinearity. Table S3A Estimated Change in Newborn Birth Weight by Relevant Maternal and Newborn Factors by Race for African Americans. Table S3B. Estimated Change in Newborn Birth Weight by Relevant Maternal and Newborn Factors by Race for non-African Americans. (DOC 64 kb)

Additional file 2: Figure S1. Change in maternal demographics over time. A Change in maternal race over time B Change in Maternal comorbid conditions of HTN and DM over time. C Change in mean Maternal Body Mass Index over time. (JPEG 55 kb)

Additional file 3: Figure S2. Correlation between Ponderal Index and percent of neonatal body fat as measured by the PeaPod. (JPEG 52 kb) 


\section{Abbreviations}

AGA: Average for gestational age; BMl: Body mass index; BW: Birth weight; LGA: Large for gestational age; PI: Ponderal index; SGA: Small for gestational age.

\section{Competing interests}

The authors declare that they have no competing interests.

\section{Authors' contributions}

KSG collected the data, performed the initial analysis, and wrote the first draft of the manuscript. TPW assisted in study design, the initial analysis, and portions of the manuscript. DDG performed the secondary and advanced statistical analysis and critically reviewed the manuscript. PMC provided guidance on the study design, assisted in data interpretation, and has critically reviewed the manuscript. All authors read and approved the final manuscript.

\section{Author details}

'Department of Obstetrics and Gynecology, MetroHealth Medical Center, Case Western Reserve University School of Medicine, 2500 Metrohealth Drive, Cleveland, OH 44109, USA. 'Loyola University Medical Center, 2160 S 1st Ave, Maywood, IL 60153, USA. ${ }^{3}$ Center for Health Care Research \& Policy, Case Western Reserve University School of Medicine, 2500 Metrohealth Drive, Cleveland, $\mathrm{OH}$ 44109, USA

\section{Received: 22 May 2015 Accepted: 4 December 2015}

Published online: 22 December 2015

\section{References}

1. Chike-Obi U, David RJ, Coutinho R, Wu SY. Birth weight has increased over a generation. Am J Epidemiol. 1996;144(6):563-9.

2. Ananth CV, Wen SW. Trends in fetal growth among singleton gestations in the United States and Canada, 1985 through 1998. Semin Perinatol. 2002; 26(4):260-7.

3. Wen SW, Kramer MS, Platt R, Demissie K, Joseph KS, Liu S, et al. Secular trends of fetal growth in Canada, 1981 to 1997. Paediatr Perinat Epidemiol. 2003;17(4):347-54

4. Bonellie S, Chalmers J, Gray R, Greer I, Jarvis S, Williams C. Centile charts for birthweight for gestational age for Scottish singleton births. BMC Pregnancy Childbirth. 2008;8:5.

5. Surkan PJ, Hsieh CC, Johansson AL, Dickman PW, Cnattingius S. Reasons for increasing trends in large for gestational age births. Obstet Gynecol. 2004 104(4):720-6.

6. Brynhildsen J, Sydsjö A, Ekholm-Selling K, Josefsson A. The importance of maternal BMI on infant's birth weight in four BMI groups for the period 1978-2001. Acta Obstet Gynecol Scand. 2009;88(4):391-6.

7. Hadfield RM, Lain SJ, Simpson JM, Ford JB, Raynes-Greenow CH, Morris JM, et al. Are babies getting bigger? An analysis of birthweight trends in New South Wales, 1990-2005. Med J Aust. 2009:190(6):312-5.

8. Oishi K, Honda S, Takamura N, Kusano Y, Abe Y, Moji K, et al. Secular trends of sizes at birth in Japanese healthy infants born between 1962 and 1988 . J Physiol Anthropol Appl Human Sci. 2004;23(5):155-61.

9. Catalano PM. Management of obesity in pregnancy. Obstet Gynecol. 2007; 109(2 Pt 1):419-33.

10. Davidson S, Litwin A, Peleg D, Erlich A. Are babies getting bigger? Secular trends in fetal growth in Israel-a retrospective hospital-based cohort study. Isr Med Assoc J. 2007;9(9):649-51.

11. Brieger GM, Rogers MS, Rushton AW, Mongelli M. Are Hong Kong babies getting bigger? Int J Gynaecol Obstet. 1997;57(3):267-71.

12. Kramer MS, Morin I, Yang H, Platt RW, Usher R, McNamara $H$, et al. Why are babies getting bigger? Temporal trends in fetal growth and its determinants. J Pediatr. 2002;141(4):538-42.

13. Donahue SM, Kleinman KP, Gillman MW, Oken E. Trends in birth weight and gestational length among singleton term births in the United States: 19902005. Obstet Gynecol. 2010;115(2 Pt 1):357-64.

14. Zhang $X$, Joseph KS, Kramer MS. Decreased term and postterm birthweight in the United States: impact of labor induction. Am J ObGyn. 2010;203(2): 124e1-7.

15. Schiessl B, Beyerlein A, Lack N, von Kries R. Temporal trends in pregnancy weight gain and birth weight in Bavaria 2000-2007: slightly decreasing birth weight with increasing weight gain in pregnancy. J Perinat Med. 2009;37(4): 374-9.

16. Grisaru-Granovsky S, Halevy T, Eidelman A, Elstein D, Samueloff A. Hypertensive disorders of pregnancy and the small for gestational age neonate: Not a simple relationship. Am J Obstet Gynecol. 2007;196(335):e1-5.

17. Heude B, Thiébaugeorges O, Goua V, Forhan A, Kaminski M, Foliguet B, et al. Pre-pregnancy body mass index and weight gain during pregnancy: relations with gestational diabetes and hypertension, and birth outcomes. Matern Child Health J. 2011:16(2):355-63. doi:10.1007/s10995-011-0741-9.

18. Steer PJ, Little MP, Kold-Jensen T, Chapple J, Elliott P. Maternal blood pressure in pregnancy, birth weight, and perinatal mortality in first births: Prospective study. BMJ. 2004;329:1312.

19. Yogev Y, Catalano PM. Pregnancy and obesity. Obstet Gynecol Clin North Am. 2009;36(2):285-300. viii.

20. Salmasi G, Grady R, Jones J, McDonald SD. Environmental tobacco smoke exposure and perinatal outcomes: a systematic review and meta-analyses. Acta Obstet Gynecol Scand. 2010;89(4):423-41.

21. McCowan LM, Roberts CT, Dekker GA, Taylor RS, Chan EHY, Kenny LC, et al. Risk factors for small-for-gestational-age infants by customised birthweight centiles: data from an international prospective cohort study. BJOG. 2010; 117(13):1599-607

22. Bhattacharya S, Campbell DM, Liston WA, Bhattacharya S. Effect of body mass index on pregnancy outcomes in nulliparous women delivering singleton babies. BMC Public Health. 2007;7:168.

23. Rode L, Hegaard HK, Kjaergaard H, Møller LF, Tabor A, Ottesen B. Association between maternal weight gain and birth weight. Obstet Gynecol. 2007;109(6):1309-15.

24. Alexander GR, Wingate MS, Bader D, Kogan MD. The increasing racial disparity in infant mortality rates: composition and contributors to recent US trends. Am J Obstet Gynecol. 2008;198(1):e1-9.

25. Study Cooperative Research Group HAPO, Metzger BE, Lowe LP, Dyer AR, Trimble ER, Chaovarindr U, et al. Hyperglycemia and adverse pregnancy outcomes. N Engl J Med. 2008:358(19):1991-2002.

26. The United States 2010 Census Data website. Available at: http://www. census.gov/2010census/data/. Accessed 23 Sept. 2011.

27. Hamilton BE, Martin JA, Ventura SJ. Births: preliminary data for 2009. National vital statistics reports; vol 59 no 03. Hyattsville: National Center for Health Statistics; 2010. http://www.cdc.gov/nchs/data/nvsr/nvsr59/nvsr59_03.pdf.

28. Curtin SC, Park MM. Trends in the attendant, place, and timing of births, and in the use of obstetric interventions: United States, 1989-97. National vital statistics reports; 47(27). National Center for Health Statistics: Hyattsville; 1999.

29. Han JC, Lawlor DA, Kimm SY. Childhood obesity. Lancet. 2010;375(9727): 1737-48.

30. Ogden $\mathrm{CL}$, Carroll MD, Kit BK, Flegal KM. Prevalence of childhood and adult obesity in the United States, 2011-2012. JAMA. 2014;311(8):806-14.

31. Amini SB, Catalano PM, Hirsch V, Mann LI. An analysis of birth weight by gestational age using a computerized perinatal data base, 1975-1992. Obstet Gynecol. 1994;83(3):342-52.

32. Alexander GR, Himes JH, Kaufman RB, Mor J, Kogan M. A United States national reference for fetal growth. Obstet Gynecol. 1996;87(2):163-8.

33. Rohrer F. "Der Index der Körperfülle als Maß des Ernährungszustandes The index of corpulence as measure of nutritional state]" (in German). Münch Med Wochensch. 1921;68:580-2.

34. Morisaki N, Esplin MS, Varner MW, Henry E, Oken E. Declines in birth weight and fetal growth independent of gestational length. Obstet Gynecol. 2013; 121(1):51-8.

35. Neufeld LM, Haas JD, Grajéda R, Martorell R. Changes in maternal weight from the first to second trimester of pregnancy are associated with fetal growth and infant length at birth. Am J Clin Nutr. 2004;79(4):646-52.

36. de Onis M, Blössner M. The World Health Organization global database on child growth and malnutrition: methodology and applications. Int J Epidemiol. 2003;32(4):518-26.

37. Luo ZC, Albertsson-Wikland K, Karlberg J. Length and body mass index at birth and target height influences on patterns of postnatal growth in children born small for gestational age. Pediatrics. 1998;102(6), E72. 